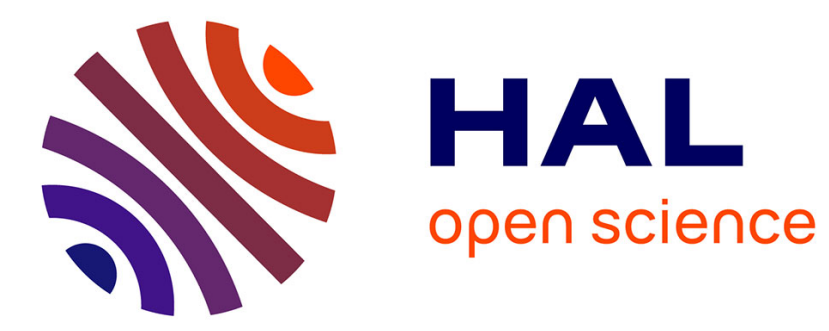

\title{
Infants preference for prosocial behaviors: A literature review
}

Claire Holvoet, Céline Scola, Thomas Arciszewski, Delphine Picard

\section{To cite this version:}

Claire Holvoet, Céline Scola, Thomas Arciszewski, Delphine Picard. Infants preference for prosocial behaviors: A literature review. Infant Behavior and Development, 2016, 45, pp.125 - 139. 10.1016/j.infbeh.2016.10.008 . hal-01464644

\section{HAL Id: hal-01464644 \\ https://hal.science/hal-01464644}

Submitted on 2 May 2018

HAL is a multi-disciplinary open access archive for the deposit and dissemination of scientific research documents, whether they are published or not. The documents may come from teaching and research institutions in France or abroad, or from public or private research centers.
L'archive ouverte pluridisciplinaire HAL, est destinée au dépôt et à la diffusion de documents scientifiques de niveau recherche, publiés ou non, émanant des établissements d'enseignement et de recherche français ou étrangers, des laboratoires publics ou privés. 


\title{
Infants' Preference for Prosocial Behaviors: A Literature Review
}

\author{
Claire Holvoet, Céline Scola, Thomas Arciszewski and Delphine Picard \\ Aix Marseille Université, PsyCLE EA3273, 13621 Aix-en-Provence, France
}

\begin{abstract}
In 2007, a study carried out by Hamlin, Wynn, and Bloom provided concrete evidence that infants as young as 6 months were capable of social evaluation, displaying an early preference for agents performing a prosocial behavior. Since then the development of early social abilities to judge other's behavior has been the topic of a growing body of research. The present paper reviews studies conducted between 2007 and 2015 that experimentally examined infants' social evaluation abilities by testing their preference for agents acting prosocially. We performed a detailed analysis of a corpus of 16 research studies including 59 experimental results, scrutinizing their methods and findings, and identifying their convergent and divergent features. This analysis showed that a preference for agents who perform prosocial behaviors (as opposed to antisocial or neutral) was present in a majority of infants, but some conflicting results have also been reported. The rich interpretation that infants are endowed with mature socio-moral evaluation abilities has not really been sufficiently discussed. In order to deepen this debate, we assessed other studies that have further explored infants' understanding of the social value of behaviors. Many of the studies provide evidence that young infants manage to identify and prefer the prosocial agent by taking into account the context and agents' mental states beyond the behavior itself. In this study two specific areas are assessed: 1) studies that have previously explored social evaluation abilities beyond a basic preference for prosocial behavior and 2) current theories which attempt to explain how and why such preferences could exist so early in infancy. Future directions for research on social evaluation abilities in infants are also discussed as well as a review of the literature. Keywords: infant; prosocial; preference
\end{abstract}




\section{Introduction}

Infants take an early interest in the people surrounding them. However, at what age do they really become capable of attributing meaning to the interactions they witness in their environment? Are social evaluation abilities rooted in innate intuitive processes or are they the result of explicit learning of social norms? These are some of the questions currently motivating an active area of research on early childhood.

Some studies (e.g., Kuhlmeier, Wynn, \& Bloom, 2003; Premack \& Premack, 1997) have demonstrated the early emergence of skills in processing interactions presented in a visual format. By using a habituation/dishabituation paradigm in which infants were shown videos of balls with different contact patterns (e.g., caressing, hitting, preventing), Premack and Premack (1997) found that infants as young as 13 months were able to attribute goals to selfpropelled (i.e., intentional) objects and assign a positive or negative value to their interactions. When Kuhlmeier et al. (2003) presented 12-month-old infants with social interaction involving cartoons of shapes, they identified an infant's ability to attribute mental states to animated entities. The aim of these studies had been to explore the representation that young children may form when they witness this type of interaction. However, their discoveries have raised questions regarding other aspects of this particular skill. For example, if infants build representations of interactions involving agents acting prosocially (e.g., bestowing an advantage or wellbeing on others) and antisocially (being harmful or preventing from achieving our goal), do they then express a preference for the agent with the prosocial behavior?

In recent years, researchers have shown considerable interest in the emergence of social evaluation abilities in young children, which are assumed to be reflected not only in their perception of prosocial behavior as appropriate, which notably implies a reaction of surprise when witnessing antisocial events, but also a preference for prosocial (vs. antisocial or neutral) agents.

Increasing evidence, reported over the past several years, has shown that infants' perceive prosocial behaviors as the social norm. When shown events depicting fair vs unfair distribution of goods, 15 and 19-month-old infants looked longer at the unfair situation, suggesting they were surprised by the inequity (e.g., Schmidt \& Sommerville, 2011; Sloane, Baillargeon \& Premack, 2012). Similarly, 10-month-old infants displayed abilities to infer the other's social preferences on the basis of their previous interactions and this gradually 
improved after their first birthday. That is to say, their visual behavior indicated that 1) they anticipated a recipient of pro- and anti-social behavior (e.g., helping vs preventing the other person from achieving their goal, allocating goods equally vs unequally) should choose to approach the agent who performed the prosocial action compared to the agent who performed the antisocial action, and 2) the infants were surprised if the recipient moved toward the antisocial agent (Fawcett \& Liszkowski, 2012; Geraci \& Surian, 2011; Hamlin, et al., 2007; Lee, Yun, Kim \& Song, 2015).

Beyond the infants' perception and expectation regarding social interaction from a third-party perspective, their preference for prosocial behaviors has elicited an increasing interest during the past decade. Given that infants cannot express their preference verbally, it must be noted that investigating which agent they preferred remains particularly difficult. Hamlin et al. (2007) were the first to identify this preference, when they found that infants aged 6-10 months were more attracted to (e.g., reaching for) characters producing prosocial behaviors than to characters producing antisocial behaviors. In agreement with the authors described above, they concluded that young children are able to assess others on the basis of the social behaviors they observe, and concluded that "the capacity to evaluate individuals by their social actions may also serve as a foundation for the developing system of moral cognition" (Hamlin, 2007, p. 558).

A number of studies focusing on infants' preferences were published in the wake of Hamlin et al.'s research (2007), who were the first to suggest infants' social abilities could be evaluated through their preferences (e.g., Buon et al., 2014; Scola, Holvoet, Arciszewski \& Picard, 2015). Among the latest research, some yielded inconsistent results and authors have offered greatly different interpretations. Consequently, we decided to review the progress made by research in this area so far, determining if evidence supporting the preference for prosocial behaviors are more numerous than ones suggesting the reverse and exploring the moderators that could influence this preference as well as the different avenues proposed by researchers to explain human early spontaneous tendency to prefer prosocial behaviors.

The present review has two main aims: the first was to provide a summary of the studies that have experimentally tested early social evaluation skills in infants (through their expressed preference for prosocial agents) since Hamlin et al. (2007), and the second was to gather current theories which could account for the early emergence of socio-moral competencies. More specifically, we set out to i) identify what has been achieved between 2007 and the present paper in this area of research, focusing on both the convergent and the divergent 
features of these studies, ii) review the main conceptual frameworks which have been proposed to explain early tendencies to prefer prosocial agents, and iii) discuss possible avenues of future research on social evaluation abilities in infants.

We could not ignore that third-party social evaluation' abilities are often explored in conjunction with first-party prosocial behavior, as sharing or helping (Cowell \& Decety, 2015a; Cowell \& Decety, 2015b; Sommerville, Schmidt, Yun \& Burns, 2013). However, in this paper we made the choice to focus only on third-party social evaluations through infants' preference for prosocial agents. We attempted to identify under which conditions this preference has or has not been found, as some conflicting results suggest this particular issue deserves interest.

We proceeded in three stages. First, we listed all the studies that have investigated infants' preference for agents behaving prosocially and performed detailed analyses of this corpus. These analyses were conducted in order to establish the nature of the methods implemented in the studies, the results they yielded (e.g., whether or not there was a preference for a prosocial agent), and the areas of agreement and disagreement to explain this preference. Second, we reported studies that have investigated infants' preference in social scenarios in which several cues where available in addition to the agent's behavior (e.g., the intention of the agent, its appearance, or even the own past behavior of the target). Finally, we examined theoretical proposals that have been provided both by authors that have conducted experimental research and by authors who proposed an outside perspective. Third, in the light of these data, we looked at where research on infants' social evaluation abilities should go from here.

\section{Studies selection method}

We searched for all the experimental studies published since 2007, the date of Hamlin and colleagues' groundbreaking study, that met the following inclusion criteria: scientific paper published in an international journal; study involving infants aged from 3- to 36- months; use of a social scenario (i.e., contrasting an agent behaving prosocially with an agent behaving antisocially or neutrally); and measurement of attentional preferences (visual or gestural) for the prosocial versus antisocial/neutral agent. First, we decided to target studies that exposed infants to simple scenarios, that is, ones directly setting an agent acting prosocially against an agent acting antisocially or neutrally, and then measured their preference for one or the other. In a second stage, we made the choice to consider some interesting complex scenarios, in which cues another than explicit behavior are available and that could be incorporated into 
infants' social evaluation: social history of the agent, intentionality, appearance, or even attributes of either the recipient or the agent of pro- and anti-social behaviors. However, considering our main aim was to explore if an overall preference for one behavior exists, this second part of the results were not analyzed in the same way as the first ones but are reported to highlight characteristics that could influence infants' preference for behaviors.

A search of scientific databases (e.g., Google Scholar, PsycArticles, PsycINFO,

ScienceDirect) yielded 16 articles that met our inclusion criteria, 12 for the first scope of the review investigating preference when competing only behavior cues and seven, including three that are already included in the firsts 12 , for the second scope including another cues. The second objective was to further analyze studies including more cues than behavior derived from the fact that some studies have indeed simultaneously explored preference between agents who differ only by behavior and preference between agents who differ on other cues beyond behavior under several experimental conditions pointing out the importance of moderators.

\section{Results: Corpus analysis of articles with simple scenario}

Table 1 summarizes the main characteristics of these 12 studies testing infants' preference for prosocial behaviors when no other relevant characteristics are thought to be available. To make it easier to analyze the various methodologies and findings, and identify the areas of agreement and disagreement within this corpus, for each of the studies, we recorded the age of the participants, the nature of the scenario, the type of material, the type of test and behavioral measure, and the results. It should be noted that as some of these studies tested more than one scenario and/or with more than one age group and/or in more than one experimental condition, this finally resulted in a set of 27 experimental results. To each of them we assigned an identification number used for in-text references when more than three are cited.

\subsection{Background to the studies}

As indicated in Table 1, research in this area was pioneered by Hamlin and colleagues, and their 2007 study gave rise to a regular flow of publications. Most of the studies we found were carried out in either North America $(n=7 / 12)$ or Europe $(n=4 / 12)$ with one sole study being conducted in New Zealand.

\subsection{Ages studied}


We can also see from Table 1 that these studies included a population of young children aged between three and 36 months. Seminal studies mainly focused on preverbal infants, 3-12 month-old being the targets of the two-thirds of the studies reported $(n=8 / 12)$, three concerned toddlers, and one compared one group of each age range (10- to 16- months). We can already observe the few attempts to adopt a developmental approach, as most studies only examined one or two age groups. Sample sizes were relatively comparable, with the majority of studies involving samples of between 8 and 25 infants for each age group. Only three have larger samples of more than 30 (Buon et al., 2014; Burns \& Sommerville, 2014; Cowell \& Decety, 2015a).

\subsection{Social scenarios presented to infants}

In order to study social evaluation in infants, researchers have to somehow get their young participants to witness social interactions. They have used a number of different social scenarios for this purpose, each generally featuring three characters: 1) an agent who performs a prosocial behavior; 2) an agent who performs an antisocial or neutral behavior (i.e., performing neither pro- nor anti-social actions); and 3) a character who is the recipient of the two agents' behaviors. As shown in Table 1, the studies in our corpus used six different scenarios, each described below. At this step, we want to point out on the plurality of the scenarios: among the 12 studies reviewed, six different scenarios have been designed. Even though this diversity allows us to investigate the preference for prosocial behaviors through a wide range of social interactions, comparisons between different research is consequently far less meaningful.

Climbing the hill is a scenario in which one of the characters is shown trying to climb a hill. A gentle slope ends in a terrace, and then there is a steeper section up to the top. This character only manages to complete the first section, and is alternately helped by a prosocial agent (the helper), who pushes him up the hill, and hindered by an antisocial agent (the hinderer), who pushes him down again. This scenario was first used to study infants' preference for prosocial behavior by Hamlin and colleagues (2007), who implemented a procedure originally devised by Kuhlmeier et al. (2003). It has since been reused on several occasions by these authors, as well as by others (e.g., Cowell \& Decety, 2015a; Scarf, Imuta, Colombo \& Hayne, 2012).

In Opening a box to get a toy, the interaction centers around a clear plastic box containing a toy. One of the characters, tries to open the box, but is unable to lift the lid, which looks too heavy. He is alternately helped by a prosocial agent (the opener), who helps him lift the lid to 
open the box, and hindered by an antisocial agent (the closer), who slams the lid shut by jumping on it. This scenario was also devised by Hamlin and Wynn (2011), and has been reused several times, mainly to replicate results (e.g., Salvadori et al., 2015).

In Retrieving a dropped ball, a character is bouncing a ball that eventually escapes, rolling toward one or the other agents waiting in the wings. The prosocial agent (the giver) picks the ball up and tosses it back to the character. The antisocial agent (the taker) also picks the ball up, but goes off with it instead of sending it back. Yet again, this scenario was created by Hamlin and Wynn (2011), who have so far been the only ones to use it.

Allocating goods is a scenario that features two animal characters waiting to receive toys. The agent who brings goods is either prosocial, and therefore distributes them equally, or antisocial, and therefore distributes them unequally. To date and in the context of testing infants' preferences, this scenario has been used by Geraci and Surian (2011) and Burns and Sommerville (2014). It has also been used by Schmidt and Sommerville (2011), Sloane et al. (2012) and Sommerville et al. (2013), however their purpose was to assess infants' expectations, and that is why we made the choice to exclude their studies for the present review as their topic focuses on infants' preferences.

Comforting \& threatening a little girl involves three human characters (two adult men and a little girl) and one inanimate object (a backpack). One of the male adults is a prosocial agent, who comforts the girl and threatens the bag, while the other is an antisocial agent, who comforts the bag and threatens the little girl. As before, this scenario has so far only been used by its creators, Buon et al. (2014).

Playing a ball game features an interaction between three characters. A character throws a ball to one of the agents as an invitation to play. The prosocial agent (the giver) sends the ball back to him to continue the game, whereas the antisocial agent (the keeper) keeps the ball and runs off with it. This scenario was developed by Scola et al. (2015) on the basis of the Retrieving a dropped ball scenario created by Hamlin and Wynn (2011).

These six social scenarios provide a means of assessing young children's sensitivity to different types of prosocial behaviors: help and cooperation in the case of Climbing the hill, Opening a box to get a toy and Retrieving a dropped ball, the notions of sharing and fairness in Allocating goods, benevolence in Comforting \& threatening a little girl, and sharing and social reciprocity in Playing a ball game. Table 1 shows that the studies conducted so far have 
mainly portrayed helping, cooperation and sharing behaviors. Each of the other prosocial behaviors has only been played out in a single scenario and assessed in a single study.

Here we describe these social scenarios in their original form, as it is worth noting that some of them (Climbing the hill, Opening a box to get a toy, and Retrieving a dropped ball) have also been adapted for use under control conditions. Control scenarios generally unfold in exactly the same way as the social scenarios, the only difference being that they involve inanimate, rather than animate, entities, to ensure that the situation is devoid of all social aspects. These control conditions are included to rule out the possibility that infants' social preferences are actually based on a preference for the perceptual aspects of one particular movement. All of those scenarios were conducted successfully.

\subsection{Different stimuli to represent social scenarios}

Social scenarios are designed to bring about interactions between agents presented as either three-dimensional (3D) or two-dimensional (2D) stimuli.

The 3D stimuli in the studies we examined were either wooden blocks or hand puppets, and Hamlin, Wynn \& Bloom (2007, 2010), and Hamlin \& Wynn (2011) were the first to used them. Only one has presented a live display involving real human actors (Burns \& Sommerville, 2014). The animated wooden blocks, which have only ever been used in the Climbing the hill scenario, have eyes and come in different geometric figures and colors. Hamlin and Wynn (2011) were also the first to use plush animal hand puppets (cats, rabbits, lions, etc.), which have so far have only been featured in the Opening a box to get a toy and Retrieving a dropped ball scenarios.

The 2D stimuli routinely appear in videos: either movies with actual human actors (used by Buon et al., 2014) or cartoons featuring characters (Cowell \& Decety, 2015a), which some that are meant to represent animals (used by Geraci \& Surian, 2011) or humans (used by Scola et al., 2015). 2D stimuli also included video recordings of displays involving 3D stimuli (wooden blocks) that have been used in the most recent studies (Hamlin, 2014a).

Once again, we should note the heterogeneousness of the stimuli and stimuli we could easily assume the attributes infants assign to each of them could greatly vary from one to another. In other words, the use of puppets, animal pictures or wooden blocks, even if probably reflecting an effort on the researcher's part to increase the attractiveness of the material, questions to which extent infants consider they exactly have the same fundamental characteristics as 
humans. However, we can already notice that the preference for agents producing a prosocial behavior is found in studies using characters representing humans (Buon et al., 2014; Burns \& Sommerville, 2014; Scola et al., 2015) as well as in studies resorting to more attractive agents like puppets (Hamlin \& Wynn, 2010; Hamlin, 2014).

\subsection{Types of tests and behavioral measures}

As shown in Table 1, the studies in our corpus implemented two main types of tests: manualchoice tests and tests of visual preference. The former were more widely used ( $n=24 / 27$ experimental conditions), and the associated behavioral measure was reaching behavior-since Hamlin et al. (2007) used this cue to assess infants' social evaluation abilities. Among the remaining three, one used the two types (Hamlin \& Wynn, 2011) and one focused only on visual preference (Hamlin et al., 2010).

In the studies featuring a manual-choice test, after being exposed to a social scenario, the infants were shown the prosocial and antisocial agents together, and asked to choose between the two. In the case of 3D stimuli, and for video recordings of 3D stimuli, experimenter directly presented the agents (wooden blocks or puppets) to the infants. In the case of 2D stimuli, we found two different methods. In studies conducted by Geraci and Surian (2011) and Scola et al. (2015), pictures of the agents were mounted on foam board (approx. $15 \mathrm{~cm}$ tall) so that the infants could reach out to grasp them. In contrast, in the Buon et al. (2014) and in the Burns \& Sommerville (2015) studies, where the scenario was played out in either a movie featuring human actors or a live display with human actors, specific apparatus had been created so that infants could choose between the same toys offered simultaneously by the two agents. In manual-choice tests, a preference for one of the agents was recorded when the infant produced a reaching gesture and/or managed to grasp the agent or toy. The reaching gesture was only deemed valid if the infant also visually looked at the chosen target.

In most studies based on looking times measures, this choice appears to have been dictated by the very young age of the participants ( 5 months or less). Before 5 months, infants only have limited motor abilities, which means we cannot be certain of the validity of their reaching gestures. Some of the studies targeting particularly young children $(n=2 / 12)$ therefore relied on purely visual indicators. Using the visual preference paradigm, researchers (Hamlin et al., 2010; Hamlin \& Wynn, 2011), measured the average amounts of time infants spent looking at the prosocial and antisocial agents, who were presented simultaneously. They made the hypothesis that the infant would look the longest at the agent they preferred. It is worth 
pointing out that interpreting looking times in terms of preferences remains quite controversial. According to Tafreshi, Thompson, and Racine (2014), they should only be interpreted as reflecting high-level processes if a significant number of conditions are met.

\subsection{Review of the findings}

Table 1 shows that out of the 27 experimental results we identified, 18 allowed the authors to conclude that infants in their study had a significant preference for the prosocial agent, 8 led to the conclusion that they had no preference, and one result pointed to a significant preference for the antisocial agent. Therefore, two-thirds of our results (67\%) indicated that young children prefer a prosocial agent over an antisocial or neutral one. The conflicting results in the remaining 10 experimental conditions might challenge the claim that infants express a strong preference for prosocial behavior. We therefore analyzed the cases where a preference was found, then the cases where none was observed, in order to identify the conditions for its expression.

Among these 18 positive results, the preference for the prosocial agent was exhibited by infants aged 3 months $(2 a ; 3 d), 5$ months $(3 a ; 3 c ; 6), 6$ months $(1 a ; 1 c), 9$ months $(3 b ; 9 a ; 9 c)$, 10 months (1b; 1d; 5a; 7), 15 months (8), 16 months (4b) and from 12- to 36- months (12a ; $12 \mathrm{~b})$. It was elicited by all the six scenarios, whether they featured 3D or 2D stimuli, and was expressed both through reaching gestures and through looking times.

First, we want to cast light on Scarf et al. (2012)'s results, as he and his colleagues were the first to question the existence of a preference for prosocial behavior. That is to say, Scarf et al. (2012) criticized Hamlin et al. (2007)'s Climbing the hill scenario for associating the prosocial agent with a positive perceptual event, claiming that the climber's bouncing constituted a confounding variable because infants find this activity amusing. The infants' preference for the prosocial agent could therefore be attributed to the latter's association with what was a positive perceptual event. When Scarf et al. (2012) manipulated this scenario, associating the bouncing either with the antisocial agent (Cond. 2) or else with both agents at the same time (Cond. 3), they found that the 10-month-olds in their sample either chose the antisocial agent (Cond. 2) or else failed to show a preference for either agent (Cond. 3), confirming the attractiveness of the bouncing event. These results led the authors to argue that infants' preferences are guided by perceptual events, rather than by their social evaluation skills. Hamlin (2014a) responded to this by conducting a further experiment to demonstrate that it was a flaw in the material used by Scarf et al. (2012) that accounted for the infant's 
failure to express a preference. More specifically, she pointed out that the target's gaze was not directed up the hill contrary to their own original material. After replicating Scarf et al.'s negative result by reusing their own material (Cond. 2), Hamlin devised two new conditions, one where the target's gaze was oriented toward his goal but who did not perform any bouncing (Cond. 3) and one the target's gaze was not oriented but performed bouncing (Cond. 4). By doing so, Hamlin (2014a) was able to demonstrate that 1) in the absence of positive perceptual events (e.g., bouncing), infants prefer the prosocial agent when the target's gaze is oriented toward his goal (Cond. 3), and 2) infants cease to express a preference when the target's pupils point down the hill (and thus suggesting an inconsistent goal), even in the presence of a positive perceptual event (Cond. 4). By refuting Scarf and colleagues' criticism, Hamlin (2014a) therefore provided additional support for her hypothesis of early social evaluation skills as she probed that an inconsistent cue regarding a social agent's goal interferes with infants' interpretation of the situation.

We considered crucial to mention those results as they have highlighted the importance of very fine details. However, as methodological flaws done either on purpose or by accident have been established, those failures are not included in the studies taken into account to determine if a preference for prosocial behaviors exists early in infancy

Thus, if we exclude the four results addressed above, 5 experimental conditions remain that reported no preference. These non-significant results were observed in young infants aged of 3 months (2b), 9 months (11a; 11b), 10 months (4a), 12-24 months (10). It is interesting to note that among these results reporting no preference or preference for an antisocial agent, two studies were failed attempts to replicate Hamlin and colleagues' seminal studies using similar scenarios and stimuli (Cowell \& Decey, 2015a; Salvadori et al., 2015). In the section below we propose a further analysis of these 5 failures to observe a preference for prosocial behaviors.

Some experimental conditions that did not reveal any preference for a prosocial behavior could be quickly explained referring to developmental accounts (Geraci \& Surian, 2011, Hamlin et al., 2010). At 3 months, Hamlin and colleagues (2010) reported three interesting results: if there are competing pro- and anti-social agents, infants prefer the prosocial one. However, when a prosocial agent competed with a neutral agent, the infants' preference disappeared. Finally, when showing an antisocial agent and a neutral agent, their preference goes toward the neutral character. These authors concluded that very early social evaluation are characterized by a negativity bias resulting in an aversion for antisocial behavior at 3 
months, that will combine with a preference for prosocial later in development. Therefore, this result should rather be considered as an evidence of an overall preference for prosocial behavior. Regarding the results reported by Geraci \& Surian (2011; e.g., a preference at 16 months but no preference at 10), a developmental hypothesis could also be argued as several studies have observed glimpses of understanding about fairness at about 15 months but not before (Schmidt \& Sommerville, 2011; Sommerville et al., 2013).

The failed attempts of replicating Hamlin and colleagues' results reported by Cowell and Decety (2015a) and Salvadori et al. (2015) raise more complex issues. Following the precise methodology and advice provided by Hamlin, Salvadori et al. (2015) there was never any success in observing a preference for a helping the puppet in the "Opening a box to get a toy" scenario. Cowell and Decety (2015a), showing cartoons of the "Climbing a hill" scenario also did not find the preference that was expected considering the repeated findings Hamlin and his team reported with the same social scenario (Hamlin et al., 2007; 2010; Hamlin, 2014a). However, differences comparing their methodology and those of all the other studies cited in this paper have to be considered (e.g., events shown randomly and not in alternation, EEG recordings) and could be considered to explain their failure. In other words, two studies focusing on the same behavior (i.e., the selective reproduction of others' goals at 7 months; in Hamlin, Hallinan \& Woodward, 2008; Filippi et al., 2016) produced evidence that wearing EEG caps could undermine behavioral effects (i.e., a systematic reproduction that falls to $49 \%$ with EEG caps, a phenomenon that obviously could also account for the failure of Cowell \& Decety (2015a). Moreover, the age of the infants tested (12-24 months), older than those of the infants encountered by Hamlin and colleagues (between 3 and 10 months), could have been a potential element to consider. However, Scola et al. (2015), even if using another scenario, report evidence sustaining a preference for a prosocial behavior with this age range. Thus, even though age does not seem to be the key to answer the question raised by these failures, it still seems to be a factor to take into account, notably considering previous considerations about developmental trajectories. All the same, using eye-tracking measures, Cowell \& Decety (2015a) found that infants look longer during the cartoons themselves to the agent acting prosocially. This result also produces evidence for an early preference for prosocial agents even if reported with another kind of measure, more recently used in this field and that was therefore not considered in this review.

At this point, having considered that these elements permit us to reach a new viewpoint of the review conducted here, we must exclude the following: the experimental conditions in which 
methodological particularities (Cowell \& Decety, 2015a), methodological flaws (Hamlin, 2014a; Scarf et al., 2012) or developmental accounts (Geraci \& Surian, 2011; Hamlin et al., 2010) could explain failures, we end-up with 19 results: 17 indicating a preference for a prosocial behavior $(90 \%)$ and 2 reporting no preference, bringing more support to the claim infants' demonstrate a preference for agents acting prosocially.

In summary, the above-mentioned findings are overall congruent with the claim that infants do prefer agents performing prosocial behaviors $(n=17 / 19$ results $-90 \%)$. The remaining failures observed in Salvadori et al. (2015) study leads to the question of what is necessary, and what could have been lacking in their procedure, to elicit social evaluation and consequently to identify the preference for prosocial behavior in infants.

Furthermore, behavior in daily life is rarely the only element available to assess a social agent, and other characteristics could influence the way we perceive their behavior. Which of these characteristics infants incorporate in their evaluation and from when is a question fresh studies have explored and found to affect preference for prosocial behavior, therefore we decided to dedicate the next section to identifying the characteristics.

\section{Additional analysis of articles with complex scenario}

Table 2 summarizes the main characteristics of seven studies including testing infants' preference for prosocial behaviors when other cues considering intentionality, social history, or appearance are available in scenario presented to infants. Regarding the table, the prosocial agent is the one who produced a behavior that, without considering any outcome, should be considered as prosocial.

We reported seven different papers (three already mentioned in the previous section), including 34 experimental conditions and results. Among these 32 results, 15 indicate a preference for the agent performing the prosocial behavior, 12 indicate no preference, and five a preference for the agent performing the antisocial behavior.

Primarily, five moderators could be identified in the scenarios created by the researchers. Three dimensions characterized the target of the behaviors: its social history (if it had itself performed a pro- or anti-social action, or been the victim of another antisocial behavior), its personal taste (either similar or dissimilar to those of the infant), and its appearance (of the same vs other-race of infant's). The two other characterize the agents: their appearance (of the same vs other-race of infant's; or scrambled-face) and their knowledge states/intention (pro- 
vs anti-social). We want to point out at this point that infants' perception and understanding of intentionality is a huge topic for which numerous papers could be mentioned but, to our knowledge, practically only Hamlin (2013a; Hamlin et al., 2013b) have explored its influence on preference for social agents.

The adult's mature social evaluation does take into account all these dimensions, even if some are more relevant if we consider social evaluation as a means to identify a beneficial partner. From this point of view, acting antisocially could sometimes be positively evaluated, for example, to punish someone that had previously been antisocial toward a third-party. Results reported by Hamlin, Wynn, Bloom \& Mahajan (2011) suggest that by 8-months, infants are able to make this context-dependent evaluation, preferring 1) an agent acting prosocially toward a target that had itself either performed a prosocial behavior, or been the victim of an antisocial behavior in a previous interaction, and 2) an agent acting antisocially toward a target that had been antisocial. Even if their first findings (Hamlin et al., 2011) indicate that nuanced social evaluation based on the context in which behaviors occur are not present before 8 months, using a methodology more appropriate to very young infants, Hamlin (2014b) found that they are actually able to produce this kind of evaluation as young as 4,5 months of age. Beyond social history of the target, infants' social evaluation also take into account the possibility of mutual affiliation with it by the identification of social category membership in terms of race and personal tastes (Burns \& Sommerville, 2014; Hamlin, Mahajan, Liberman \& Wynn, 2013). Therefore, as young as 9 months, infants' preference for prosocial agents disappear or reverse to antisocial ones insofar as the target expressed contrasted different tastes (Hamlin et al., 2013a) or if it belongs to another race (Burns \& Sommerville, 2014). Overall, these results indicate 1) infants' preference for behaviors are highly sensitive to potential affiliation with the target and 2) that intergroup biases seem to emerge early in infancy and influence infants' social evaluations (and consequently their preference for prosocial behaviors) to the same extent as adults' ones.

Regarding moderators about the agents, perceptual changes about appearance are taken into account when infants assess social evaluation. First, social category membership based on race have been found to interfere with infants' social evaluation (Burns \& Sommerville, 2014; Scola et al., 2015). Once again, infant's preference for prosocial agents disappears insofar as one of the agents, irrespective of the valence of their behavior, is from another race than that of the infant. Second, showing agents displaying odd facial features (i.e. a scrambled-face), infants do not express preference anymore (Scola et al., 2015). Finally, considering that a 
behavior could be valued through 2 viewpoints - their outcome and the underlying intention results reported that, as adults, 8-month-old, but not 5-month-old, infants' social evaluation rely on the most relevant cue: intention (Hamlin, 2013a; Hamlin, Ullman, Tenenbaum, Goodman \& Baker, 2013b). Even if the behavior ends in a negative outcome, infants manage to identify the agent displaying a prosocial intention and display a preference for (Hamlin, 2013a). Furthermore, 10-month-old infants are able to accurately analyze the knowledge states of the agent, on the basis of what the agent has witnessed (or not witnessed) about the target's personal taste, and to infer whether their subsequent behavior could be considered as prosocial (Hamlin et al., 2013b).

In summary, studies that have proposed scenarios to infants in which more cues than only behavioral ones, have highlighted that very early in infancy, infants' social evaluation are as flexible as the adults and influence, when appropriate, their preference for prosocial behavior. Social category membership, the social history of the target, or even the intention are incorporated in their assessment of social situations at an early stage.

Therefore, we have reviewed all the results which deal with experiments investigating infants' preferences for prosocial behaviors in simple and complex scenarios. Overall, most findings are in agreement with the idea that infants, in fact do, express a preference for prosocial behavior, even though there have been some failures to observe it (mainly Salvadori et al., 2015) no authors have found any explanation to date. Furthermore, fresh evidence suggests infants' preference for prosocial behavior is flexible and that elements of the context are incorporated in their social evaluation early in development. However, to our knowledge, no study has objectively established the mechanisms underlying this phenomenon. Nevertheless, several hypotheses have been proposed to explain them and are outlined in the following section.

\section{Current theories explaining the early preference for prosocial agents}

The first aspect for consideration in this regard is that this burgeoning area of research is relatively recent, and additional studies are needed to clarify the underpinnings of these preferences. To date, no consensus exists regarding a conceptual framework which could explain why we are, so early in ontogeny, able to judge these social agents according to the valence of their behavior toward a third person. As mentioned above, only one low-level interpretation of these preferences has been put forward by Scarf et al. (2012): the perceptual account, suggesting infants prefer a prosocial agent because of its association with a positive 
perceptual event. Considering that this explanation has been ruled out by Hamlin (2014)'s research that has identified methodological flaws and a lack of social cues in their material, we consider infants' choices are more likely driven by mid- or even high-level processes. Given an increasingly number of studies providing data to support mentalistic accounts of this phenomenon (as described below), we made the choice to focus on social accounts. The last

point we want to clarify is that, even if the simple dichotomy "innateness vs socialization" is no longer relevant, we have made a distinction between conceptual frameworks which consider that infants' preferences are rooted in innate intuitions and those which offer a more constructivist viewpoint in order to clarify this theoretical challenge.

\subsection{Infants' preferences reflect innate socio-moral intuitions}

This first conceptual framework suggests mechanisms that are involved in processing the social scenario presented to infants deal with social competencies. Indeed, authors who reported the preference for prosocial behaviors have attributed this spontaneous preference to infants' early social evaluation abilities. In other words, they deemed that their youthful participants positively evaluated the prosocial agent and negatively evaluated the antisocial agent on the basis of their pro- or anti-social behaviors toward a character.

Hamlin et al. go further claiming that their accumulating findings probe the existence of " $a$ n innate moral core" in infants and toddlers (Hamlin, 2013b). According to these author and her team, infants are endowed with a moral reasoning system which could be compared to an adult. Thus, and as previously stated, the experiments they conducted following her first findings reported that infants, beyond assessing agents on the basis of their behavior, are able to take into account the social context in which they occur (Hamlin, 2014a) and agents' mental states (Hamlin, 2013a). This conclusion has also been reported by recent studies led by others teams of research, including one (Lee, Yun, Kin \& Song, 2015) which have used the same material and scenario Hamlin and colleagues (2007) proposed in their pioneer study. Moreover, Hamlin et al., (2013b) showed that knowledge states influence 10-month-old infants' evaluation of social agents, a finding also supported by other researchers (Choi \& Luo, 2015). Thus, she considers these results as evidence for built-in foundations of a mature moral sense. In the same way, Kanakogi, Okumura, Inoue, Kitazaki and Itakura (2012) demonstrated that 10-month-old infants who witness third party interaction involving pro- and anti-social behaviors, exhibit a preference for the victim and avoid the aggressor, suggesting they have an understanding of the consequences of the behaviors and could display empathy for recipients of antisocial ones. Hamlin (2013b) claimed the innateness of these abilities 
arguing i) young infants have arguably, few experiences of moral interactions, ii) that the ability to select an appropriate partner is particularly important when one's survival depends on others (as is the case for very young children), and so could be considered to have an adaptative function, and iii) the preference infants display in these studies match with their own behavior: when giving the choice to reward and punish pro- and anti-social puppets, 19 month-old infants choose to reward the former and to punish the latter (Hamlin et al., 2011b). In addition, an overall preference for prosocial behaviors could be inferred through 16-monthold infants choice to selectively gather information from prosocial agents (and not from antisocial ones) (Hamlin \& Wynn, 2012) and through 26-month-old toddlers engagement in preferential helping toward a prosocial agent (Dahl, Schuck \& Campos, 2013). Sheskin, Chevallier, Lambert, and Baumard (2014) give support, with reference to the life-history theory (an approach in evolutionary biology) to the proposal that natural selection could have favored the early emergence of third-party social evaluation. That is, these abilities, allowing infants to distinguish between potential friends and foes, could emerge at such an early stage because they are a key to their survival.

However, we could arguably assume these abilities undergo developmental changes, such as many other abilities in infancy. For example, Sommerville et al. (2013) reported that 15month-old infants were significantly more likely to share a toy than 12-month-olds. We could assume the preference for prosocial behavior, as our tendency for sharing, knows a developmental trajectory. Even if we can observe it in the first months of life, we could imagine this preference i) vanishes when infants discover the notion of ownership and are focused on their own needs, and ii) could be found again when toddlers understand the benefits that could stem from performing prosocial behaviors and have been taught some behaviors are good and others are bad.

\subsection{Social evaluation abilities should be acquired through experiences}

A second more "constructivist" assumption could be considered, as developmental changes have been reported in several studies, suggesting at least some abilities involved in social evaluation could stem from socialization. For example, Geraci \& Surian (2011) observed that at 16 months, but not 10 months, infants chose to pick up the fair distributor compared to the unfair distributor, showing they have a "sense of fairness" which guides their preference. Furthermore, intentions have been found to be considered as a more important cue than outcomes at 8 months but not at 5 months (Hamlin, 2013a). This developmental trajectory lends support that expectations and social norms are learned through experience. A conceptual 
framework arguing these abilities are rooted in early social interactions has been proposed by Govrin (2014). In this "attachment approach to moral judgment" this author speculates that infants, through their relations with their caregiver, acquire expectations on how we have to treat others, especially others who need help, allowing us to distinguish right from wrong behaviors. Two reported studies have highlighted that attachment status of infants influence their perception of social interactions involving "prosocial" (i.e. responsive) vs "antisocial" (i.e. unresponsive) caregivers in animated scenarios (Johnson, Dweck \& Chen, 2007; Johnson, Dweck, Chen, Stern, Ok \& Barth, 2010).

Globally, even if we are not in a position to adjudicate in this debate if our socio-moral abilities are a core aspect of human nature, we can assume infants, at birth, possess sociomoral intuition. Nonetheless, considering these socio-evaluative competencies have an innate basis, it does not preclude that experience may likely play a role in the acquisition of more sophisticated abilities.

However, there is one point that most authors seem to be in agreement in all studies: infants distinguish between agents who display behaviors with a prosocial value (i.e., behaviors that have a positive impact in the interaction and/or bestow an advantage or wellbeing on others and/or enable others to achieve their objective) and agents who display behaviors with an antisocial value. This distinction is supported by studies which have explored the neural correlates underlying infants' preference for prosocial over antisocial agents. Gredebäck et al. (2015) identified changes in 6 month-old infants in the activation of an ERP component known to be involved in social stimuli processing (P400) when they are shown social interactions. More specifically, observing agents that have previously helped or hindered in the "Climbing the hill" scenario, P400 response differs according to the valence of their behavior. These results are the first to provide data on the neural correlates of prosocial preferences in young infants. With older infants, Cowell and Decety (2015a; 2015b), notably using EEG and eye-tracking, have also investigated the neural underpinnings of children' social evaluation abilities, and their bonds with their temperament, their own prosocial behavior and even parental values regarding justice and fairness. They found neural differentiation in 12-month-old infants when perceiving animated entities engaged in pro- and anti-social behaviors, and that automatic and controlled processes (EPN and N2 with LPP, respectively) intervene in the social evaluation of the morally laden scenarios. Among the variables investigated, they established 1) controlled processes predict sharing behavior, leading them to link social evaluation abilities and first-party prosocial behaviors in 3- and 5- 
year-olds, and 2) parental values are bound to 12-24-month-old infants' neural processing of the scenarios. Data collected also indicate this differentiation consists more in approach/avoidance tendencies and basic resource allocation than in an expression of a mature moral sense. Despite these findings draw a less rich interpretation of infants and toddlers' preferences, they show us the potential of an integrative approach, and that neuroscience methods should provide us strength basis to have a better understanding of the mechanisms by which infants develop their social abilities.

\section{Conclusion and future prospects for research on social evaluation}

Analysis of our corpus led us to draw the following conclusions. First, a preference for a prosocial agent emerges at a very early juncture, as it was observed as early as 5 months (with an avoidance of antisocial ones as a precursor at 3 months) (Hamlin et al., 2007; 2010). We can assume that this preference extends to a whole set of prosocial behaviors, given that it was observed in a variety of scenarios illustrating different types of behavior. The failures by Cowell \& Decety (2015) and Salvadori et al. (2015) to replicate significant results and the developmental effects reported (the expression of preference in older infants) highlights the need to go further and to precisely define 1) the social cues required to find a preference for prosocial behaviors and 2) the developmental trajectories of our understanding of all social behaviors, as proposed below.

Above all, a first point that should be evoked there is a lack of consensus regarding the concepts used in the literature. That is, we currently use the terms of "moral judgment", "social evaluation", "socio-moral competencies" (we will not mention all of them here) as equivalent. However, we consider that morality and social evaluation do not reflect the same notions or conceptual considerations. Does the preference for a prosocial agent in order to avoid the one who represents a threat reflect something about morality? We may ask if social evaluation and moral evaluation are two separated concepts or whether they should be considered as similar.

The early emergence of social skills is a burgeoning area of research. To go further in the assessment of social evaluation abilities, it will be important for future studies to explore a number of hitherto neglected factors that raise fresh questions and open up new avenues of research.

For instance, what are the mechanisms which drive infants' preference? Does the preference for prosocial agents change during the first years of life? To date, most authors have studied 
preverbal infants under the age of 12 months (two-thirds of the studies reported in this review), and less data are available for the 12-36 months' age group. Studies adopting a developmental approach are needed if we are to find answers to these questions. It might also be useful to conduct comparative studies with nonhuman primates, as we could assume a potential phylogenetic relation, considering findings that have been reported for the production of prosocial behaviors in chimpanzees (Warneken \& Tomasello, 2006, 2009) or for third-party social evaluation in capuchin monkeys (Anderson, Kuroshima, Takimoto \& Fujita, 2013) and even dogs (Chijiiwa, Kuroshima, Hori, Anderson \& Fujita, 2015).

Moreover, we believe it is important to develop new methodologies in this field of research to have more accurate measures of early social abilities. For example, eye-tracking measures could allow us to precisely identify which cues are recruited by infants to make social evaluations. The failure by Scarf et al. (2012) due to the orientation of eyes invites us to explore where infants allocate attention (e.g. do they pay attention to the agent's arms, or to his face?). Identifying those elements will also highlight why some researchers fail to find evidence for early social evaluation. By using new methodologies and by integrating neuroscience methods, we would have arrived at more substantial conclusions all along infancy.

Finally, we need to approach the development of social evaluation from two angles. First, we need to explore all the variables concerning the social interactions presented to the infant. Prosocial behaviors are many and various, and if they emerge only gradually, it is because they require different levels of comprehension. Do infants become sensitive to helping, sharing, cooperation and fairness all at the same time, or only gradually? There is also more to social interactions than the valence (pro- vs. anti-social) of the agents' behaviors. For instance, infants' social evaluations also take agents' physical appearance into account. The observation that very young infants cease to express a preference for prosocial behavior when perceptual aspects are manipulated should prompt us to explore the influence of these aspects further and if a hierarchical order determining which social dimensions are considered first.

Second, researchers have so far overlooked the effect of individual differences, even though many such variables intervene in infant's social development. Only three studies have focused their interest on these kinds of factors: two carried out by Johnson et al. $(2007 ; 2010)$, who were the firsts to evoke the infant's attachment status, and one conducted by Cowell and Decety (2015a) who have collected information on infant's temperament and parental dispositions, elements that need further exploration. Moreover, to date no study, to our 
knowledge, has investigated if differences in the development of social evaluation abilities could stem from infant's differences in the quantity and quality of social interactions infants experience in their daily life. Furthermore, another question that could be raised is the influence of culture. For example, we can ask if infants growing up in collectivistic vs individualistic societies undergo different developmental trajectories regarding their social abilities. It is certainly important to identify the impact of these internal factors on the development of prosocial preference, as studies in this area would enable us to establish the nature of social cognition in infants.

\section{References}

Anderson, J. R., Kuroshima, H., Takimoto, A., \& Fujita, K. (2013). Third-party social evaluation of humans by monkeys. Nature Communications, 4, 1561. doi:10.1038/ncomms2495

Buon, M., Jacob, P., Margules, S., Brunet, I., Dutat, M., Cabrol, D., \& Dupoux, E. (2014). Friend or foe? Early social evaluation of human interactions. Plos One, 9(2), e88612. doi:10.1371/journal.pone.0088612

Burns, M. P., \& Sommerville, J. A. (2014). "I pick you": The impact of fairness and race on infants' selection of social partners. Frontiers in Psychology, 5(FEB), 1-10. doi:10.3389/fpsyg.2014.00093

Chijiiwa, H., Kuroshima, H., Hori, Y., Anderson, J. R., \& Fujita, K. (2015). Dogs avoid people who behave negatively to their owner: Third-party affective evaluation. Animal Behaviour, 106, 123-127. doi:10.1016/j.anbehav.2015.05.018

Choi, Y., \& Luo, Y. (2015). 13-Month-Olds ' Understanding of Social Interactions. Psychological Science, 26, 274-283. doi:10.1177/0956797614562452

Cowell, J. M., \& Decety, J. (2015a). Precursors to morality in development as a complex interplay between neural, socioenvironmental, and behavioral facets. Proceedings of the National Academy of Sciences, 112(41), 201508832. doi:10.1073/pnas.1508832112

Cowell, J. M., \& Decety, J. (2015b). The neuroscience of implicit moral evaluation and its relation to generosity in early childhood. Current Biology : 25(1), 93-79. doi:10.1016/j.cub.2014.11.002 
Dahl, A., Schuck, R. K., \& Campos, J. J. (2013). Do young toddlers act on their social preferences? Developmental Psychology, 49(10), 1964-70. doi:10.1037/a0031460

Fawcett, C., \& Liszkowski, U. (2012). Infants anticipate others' social preferences. Infant and Child Development, 21, 239-249. doi:10.1002/icd.739

Filippi, C. A., Cannon, E. N., Fox, N. A., Thorpe, S. G., Ferrari, P. F., \& Woodward, A. L. (2016). Motor System Activation Predicts Goal Imitation in 7-Month-Old Infants. Psychological Science, (April), 0-10. doi:10.1177/0956797616632231

Geraci, A., \& Surian, L. (2011). The developmental roots of fairness: infants' reactions to equal and unequal distributions of resources. Developmental Science, 14(5), 1012-1020. doi:10.1111/j.1467-7687.2011.01048.x

Gredebäck, G., Kaduk, K., Bakker, M., Gottwald, J., Ekberg, T., Elsner, C., Reid, V., \& Kenward, B. (2015). The neuropsychology of infants' pro-social preferences. Developmental Cognitive Neuroscience, 12, 106-113. doi:10.1016/j.dcn.2015.01.006

Govrin, A. (2014). The ABC of moral development: An attachment approach to moral judgment. Frontiers in Psychology, 5, 1-15. doi:10.3389/fpsyg.2014.00006

Hamlin, J. K. (2013a). Failed attempts to help and harm: Intention versus outcome in preverbal infants' social evaluations. Cognition, 128(3), 451-474. doi:10.1016/j.cognition.2013.04.004

Hamlin, J. K. (2013b). Moral judgment and action in preverbal Infants and toddlers: Evidence for an innate moral core. Current Directions in Psychological Science, 22, 186-193. doi:10.1177/0963721412470687

Hamlin, J. K. (2014a). The case for social evaluation in preverbal infants : Gazing toward one's goal drives infants' preferences for helpers over hinderers in the hill paradigm. Frontiers in Psychology, 5(1563), 1-9. doi:10.3389/fpsyg.2014.01563

Hamlin, J. K. (2014b). Context-dependent social evaluation in 4.5-month-old human infants: The role of domain-general versus domain-specific processes in the development of social evaluation. Frontiers in Psychology, 5, 1-10. doi:10.3389/fpsyg.2014.00614

Hamlin, J. K., \& Wynn, K. (2011). Young infants prefer prosocial to antisocial others. Cognitive Development, 26(1), 30-39. doi:10.1016/j.cogdev.2010.09.001 
Hamlin, J. K., \& Wynn, K. (2012). Who knows what's good to eat? Infants fail to match the food preferences of antisocial others. Cognitive Development, 27(3), 227-239. doi:10.1016/j.cogdev.2012.05.005

Hamlin, J. K., Hallinan, E. V., \& Woodward, A. L. (2008). Do as I do: 7-Month-old infants selectively reproduce others' goals. Developmental Science, 11(4), 487-494. doi:10.1111/j.1467-7687.2008.00694.x

Hamlin, J. K., Wynn, K., \& Bloom, P. (2007). Social evaluation by preverbal infants. Nature, 450(7169), 557-559. doi:10.1038/nature06288

Hamlin, J. K., Wynn, K., \& Bloom, P. (2010). Three-month-olds show a negativity bias in their social evaluations. Developmental Science, 13, 923-929. doi:10.1111/j.14677687.2010.00951.x

Hamlin, J. K., Wynn, K., Bloom, P., \& Mahajan, N. (2011b). How infants and toddlers react to antisocial others. Proceedings of the National Academy of Sciences, 108(50), 199316. doi:10.1073/pnas.1110306108

Hamlin, J. K., Mahajan, N., Liberman, Z., \& Wynn, K. (2013a). Not like me = bad: Infants prefer those who harm dissimilar others. Psychological Science, 24(4), 589-594. doi:10.1177/0956797612457785

Hamlin, J. K., Ullman, T., Tenenbaum, J., Goodman, N., \& Baker, C. (2013b). The mentalistic basis of core social cognition: Experiments in preverbal infants and a computational model. Developmental Science, 16, 209-226. doi:10.1111/desc.12017

Johnson, S. C., Dweck, C. S., \& Chen, F. S. (2007). Evidence for infants' internal working models of attachment: Short report. Psychological Science, 18(6), 501-502. doi:10.1111/j.1467-9280.2007.01929.x

Johnson, S. C., Dweck, C. S., Chen, F. S., Stern, H. L., Ok, S. J., \& Barth, M. (2010). At the intersection of social and cognitive development: Internal working models of attachment in infancy. Cognitive Science, 34, 807-825. doi:10.1111/j.15516709.2010.01112.x

Kanakogi, Y., Okumura, Y., Inoue, Y., Kitazaki, M., \& Itakura, S. (2013). Rudimentary sympathy in preverbal infants: preference for others in distress. PloS One, 8(6), e65292. doi:10.1371/journal.pone.0065292 
Kuhlmeier, V., Wynn, K., \& Bloom, P. (2003). Attribution of dispositional states by 12month-olds. Psychological Science, 14(5), 402-408. doi:10.1111/1467-9280.01454

Lee, Y., Yun, J. E., Kim, E. Y., \& Song, H. (2015). The Development of Infants' Sensitivity to Behavioral Intentions when Inferring Others' Social Preferences. Plos One, 10(9), e0135588. doi:10.1371/journal.pone.0135588

Premack, D., \& Premack, A. J. (1997). Infants attribute value \pm to the goal-directed actions of self-propelled objects. Journal of Cognitive Neuroscience, 9, 848-856. doi:10.1162/jocn.1997.9.6.848

Salvadori, E., Blazsekova, T., Volein, A., Karap, Z., Tatone, D., Mascaro, O., \& Csibra, G. (2015). Probing the Strength of Infants' Preference for Helpers over Hinderers: Two Replication Attempts of Hamlin and Wynn (2011). PloS One, 10(11), e0140570. doi:10.1371/journal.pone.0140570

Scarf, D., Imuta, K., Colombo, M., \& Hayne, H. (2012). Social evaluation or simple association? Simple associations may explain moral reasoning in infants. Plos One, 7(8), e42698. doi:10.1371/journal.pone.0042698

Schmidt, M. F. H., \& Sommerville, J. A. (2011). Fairness expectations and altruistic sharing in 15-month-old human infants. Plos One, 6(10). doi:10.1371/journal.pone.0023223

Scola, C., Holvoet, C., Arciszewski, T., \& Picard, D. (2015). Further Evidence for Infants' Preference for Prosocial Over Antisocial Behaviors. Infancy, 20(6), 684-692. doi:10.1111/infa.12095

Sheskin, M., Chevallier, C., Lambert, S., \& Baumard, N. (2014). Life-history theory explains childhood moral development. Trends in Cognitive Science, 1364, 1-3. doi:10.1016/j.tics.2014.08.004

Sloane, S., Baillargeon, R., \& Premack, D. (2012). Do Infants Have a Sense of Fairness? Psychological Science, 23(2), 196-204. doi:10.1177/0956797611422072

Sommerville, J. A., Schmidt, M. F. H., Yun, J., \& Burns, M. (2013). The Development of Fairness Expectations and Prosocial Behavior in the Second Year of Life. Infancy, 18(1), 40-66. doi:10.1111/j.1532-7078.2012.00129.x 
Tafreshi, D., Thompson, J. J., \& Racine, T. P. (2014). An Analysis of the Conceptual Foundations of the Infant Preferential Looking Paradigm. Human Development, 6, 222240. doi:10.1159/000363487

Warneken, F., \& Tomasello, M. (2006). Altruistic helping in human infants and young chimpanzees. Science, 311, 1301-1303. doi:10.1126/science.1121448

Warneken, F., \& Tomasello, M. (2009). Varieties of altruism in children and chimpanzees. Trends in Cognitive Sciences, 13, 397-402. doi:10.1016/j.tics.2009.06.008 
Table 1. Summary of research studies using simple scenarios to test infants' preference for prosocial behaviors. Studies are ranked in chronological order of publication. Identification number (Id) is used for easier in-text citation.

\begin{tabular}{|c|c|c|c|c|c|c|c|c|c|c|c|}
\hline $\begin{array}{l}\text { Authors } \\
\text { (Country) }\end{array}$ & $\begin{array}{l}\text { Year of } \\
\text { publicatio } \\
n\end{array}$ & Id & $\begin{array}{l}\text { Social } \\
\text { scenario }\end{array}$ & $\begin{array}{l}\text { Stimulus } \\
\text { used }\end{array}$ & $\begin{array}{l}\text { Type of } \\
\text { test }\end{array}$ & $\begin{array}{l}\text { Behaviora } \\
1 \text { measure }\end{array}$ & $\begin{array}{l}\text { Age in } \\
\text { month } \\
s\end{array}$ & $\begin{array}{l}\text { Sampl } \\
\text { e size }\end{array}$ & $\begin{array}{l}\text { Dependent } \\
\text { variable }\end{array}$ & Results & $\begin{array}{l}\text { Conclusio } \\
\mathrm{n}\end{array}$ \\
\hline \multirow[t]{2}{*}{$\begin{array}{l}\text { (1) Hamlin } \\
\text { et al. (USA) }\end{array}$} & \multirow[t]{2}{*}{2007} & $1 \mathrm{a}$ & \multirow[t]{2}{*}{$\begin{array}{l}\text { Climbing } \\
\text { the hill }\end{array}$} & \multirow[t]{2}{*}{$\begin{array}{l}\text { Wooden } \\
\text { blocks } \\
(3 \mathrm{D})\end{array}$} & \multirow[t]{2}{*}{$\begin{array}{l}\text { Manual } \\
\text { choice }\end{array}$} & \multirow[t]{2}{*}{$\begin{array}{l}\text { Reaching } \\
\text { behavior }\end{array}$} & 6 & 12 & $\begin{array}{l}\text { No. infants } \\
\text { choosing the } \\
\text { prosocial } \\
\text { agent }\end{array}$ & $12 * * *$ & $\begin{array}{l}\text { Preference } \\
\text { for } \\
\text { prosocial } \\
\text { (vs } \\
\text { antisocial) }\end{array}$ \\
\hline & & $1 \mathrm{c}$ & & & & & 6 & 8 & $\begin{array}{l}\text { No. infants } \\
\text { choosing the } \\
\text { prosocial } \\
\text { agent }\end{array}$ & $7 *$ & $\begin{array}{l}\text { Preference } \\
\text { for } \\
\text { prosocial } \\
\text { (vs } \\
\text { neutral) }\end{array}$ \\
\hline \multirow[t]{2}{*}{$\begin{array}{l}\text { (2) Hamlin } \\
\text { et al. (USA) }\end{array}$} & \multirow[t]{2}{*}{2010} & $2 a$ & \multirow[t]{2}{*}{$\begin{array}{l}\text { Climbing } \\
\text { the hill }\end{array}$} & \multirow[t]{2}{*}{$\begin{array}{l}\text { Wooden } \\
\text { blocks } \\
(3 \mathrm{D})\end{array}$} & \multirow[t]{2}{*}{$\begin{array}{l}\text { Visual } \\
\text { preferenc } \\
\mathrm{e}\end{array}$} & \multirow[t]{2}{*}{$\begin{array}{l}\text { Looking } \\
\text { time }\end{array}$} & 3 & 12 & $\begin{array}{l}\text { Mean looking } \\
\text { time } \\
\text { (pro/antisocial } \\
\text { ) }\end{array}$ & $\begin{array}{l}13.12 / 6.22 \\
s^{*}\end{array}$ & $\begin{array}{l}\text { Preference } \\
\text { for } \\
\text { prosocial }\end{array}$ \\
\hline & & $2 b$ & & & & & 3 & 12 & Mean looking & $8.17 / 8.64$ & No \\
\hline
\end{tabular}




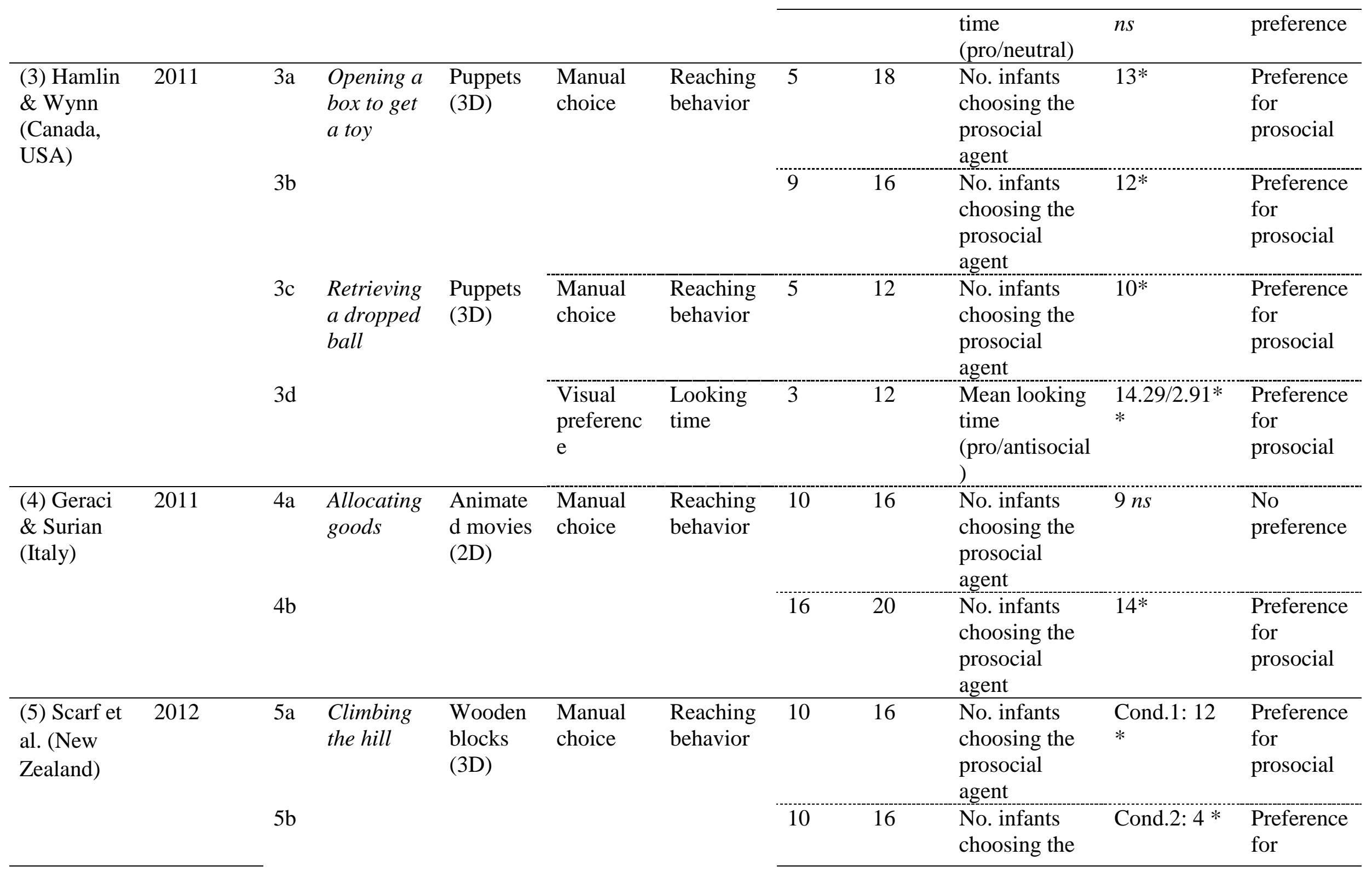




\begin{tabular}{|c|c|c|c|c|}
\hline & & $\begin{array}{l}\text { prosocial } \\
\text { agent }\end{array}$ & & antisocial \\
\hline 10 & 16 & $\begin{array}{l}\text { No. infants } \\
\text { choosing the }\end{array}$ & Cond.3: $8 n s$ & $\begin{array}{l}\text { No } \\
\text { preference }\end{array}$ \\
\hline
\end{tabular}

agent

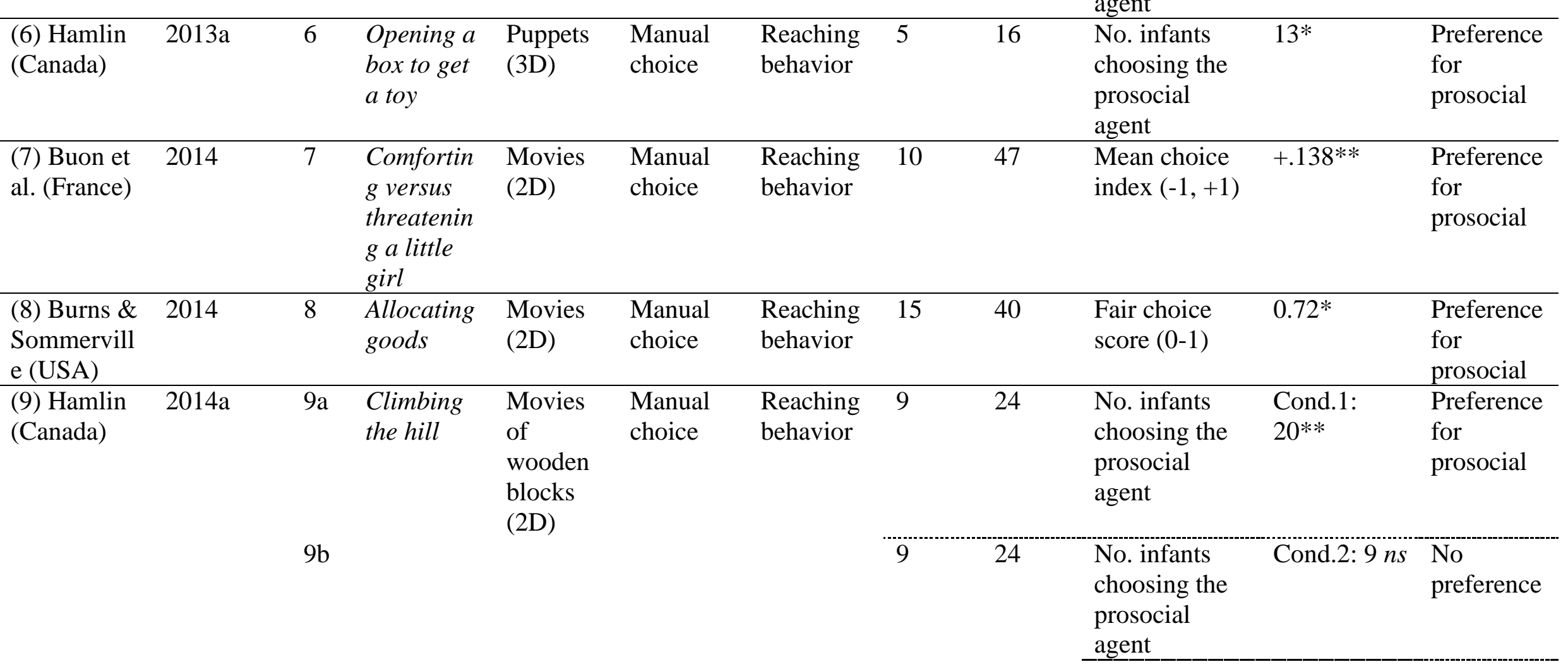




$\begin{array}{llll}925 & \begin{array}{l}\text { No. infants } \\ \text { choosing } \\ \text { the prosocial }\end{array} & \text { Cond.3: 19* } & \begin{array}{l}\text { Preference } \\ \text { for } \\ \text { prosocial }\end{array}\end{array}$
agent

$9 \quad 25 \quad$ No. infants

choosing the

Cond.4: 12 No

prosocial

agent

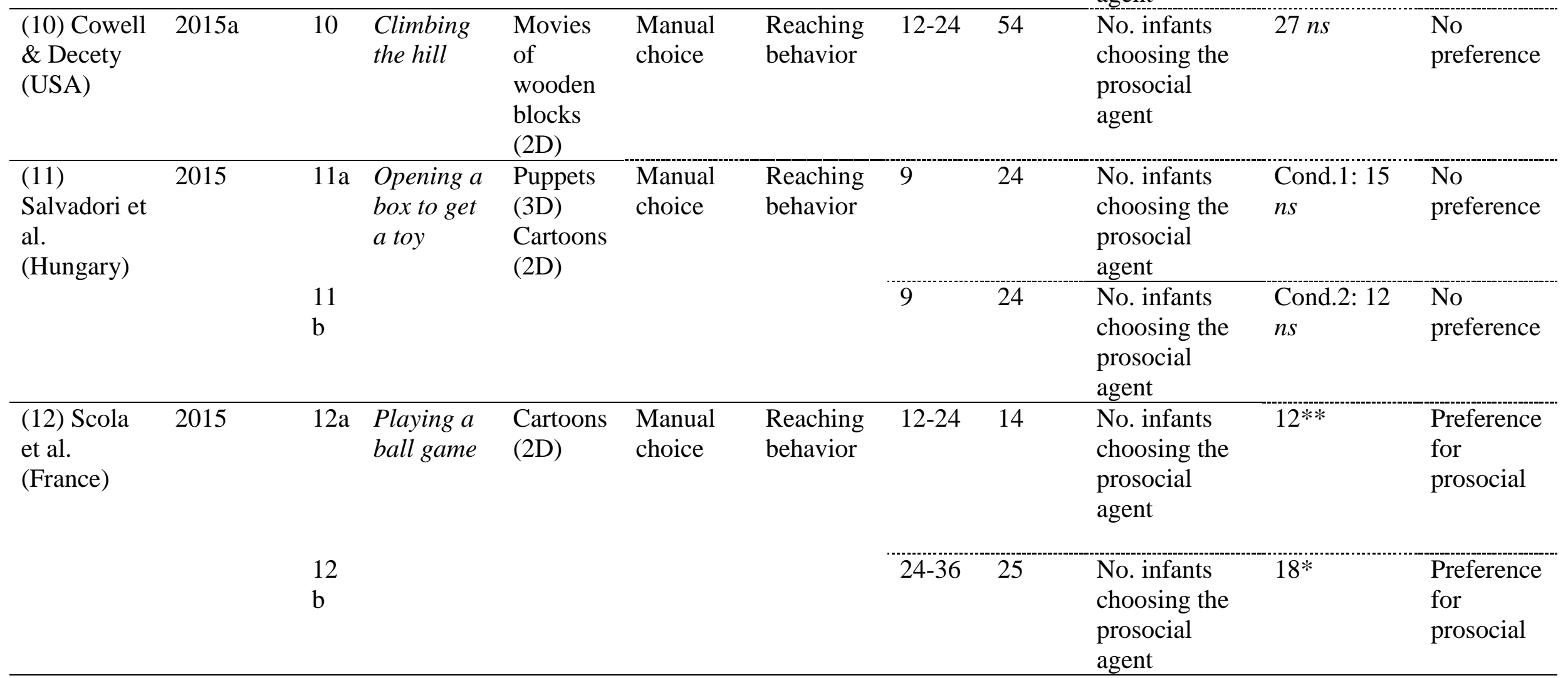

Note. $n s=$ nonsignificant at $\alpha=.05 ; \mathrm{s}=$ seconds; Cond. $=$ experimental condition. 
$*$ one-tailed $p<.05 . * *$ one-tailed $p<.01 . * * *$ one-tailed $p<.001$. 
Table 2. Summary of research studies using scenarios including moderators to test infants' preference for prosocial behaviors. Studies are ranked in chronological order of publication.

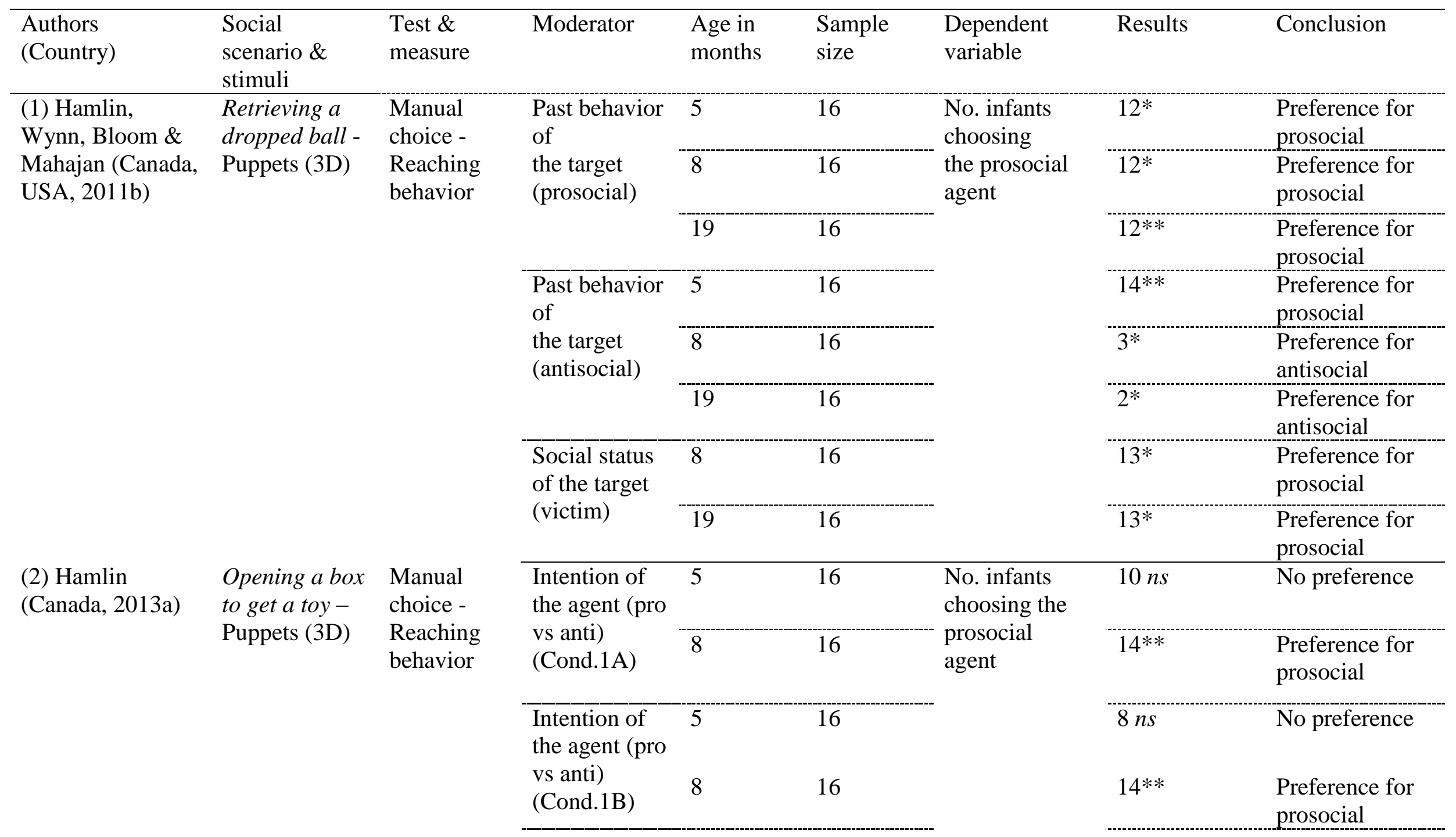




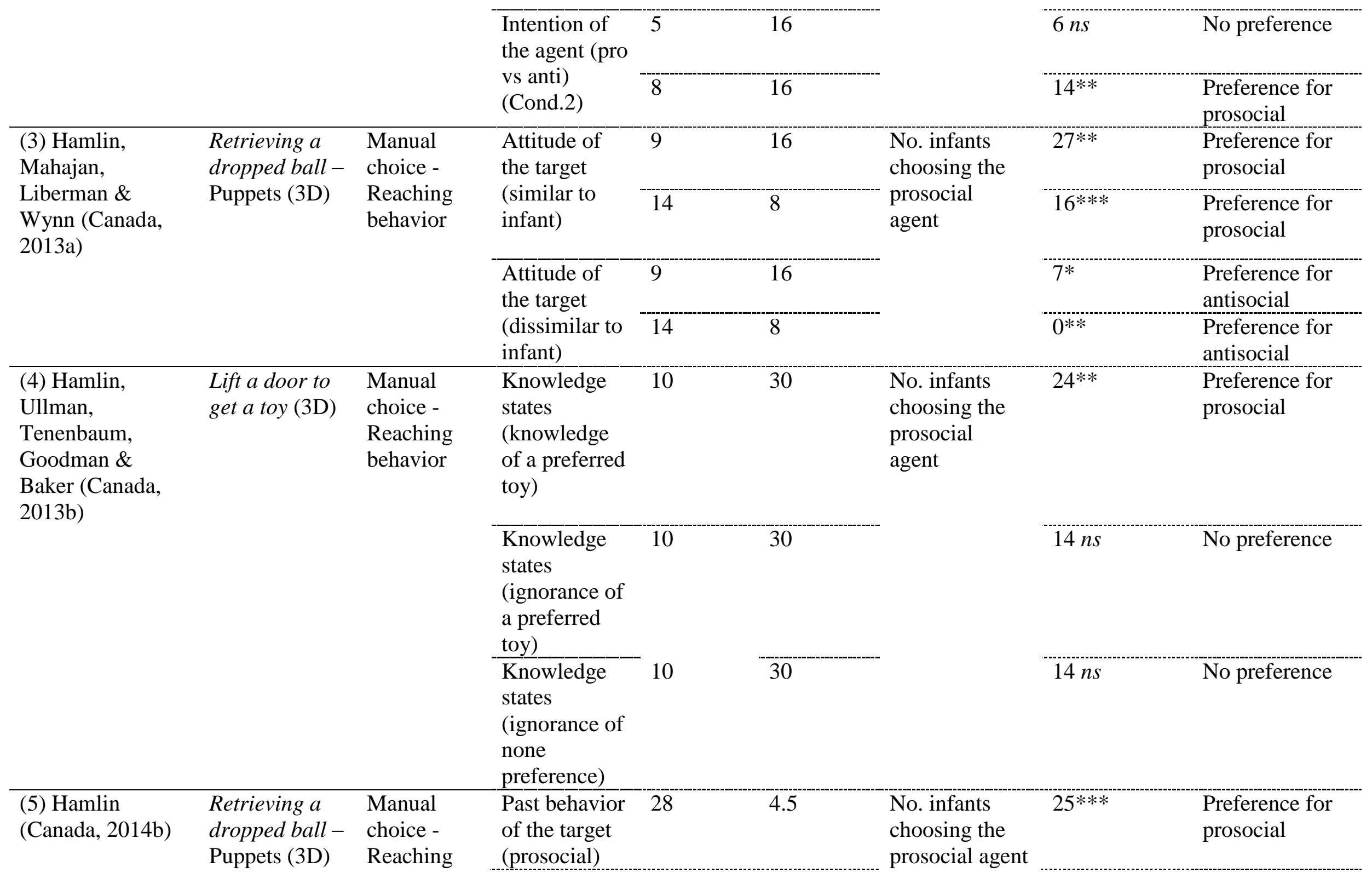




\begin{tabular}{|c|c|c|c|c|c|c|c|c|}
\hline & & \multirow{3}{*}{ behavior } & & & & & & \\
\hline & & & $\begin{array}{l}\text { Past behavior } \\
\text { of the target } \\
\text { (antisocial) }\end{array}$ & 27 & 4.5 & & $6 * *$ & $\begin{array}{l}\text { Preference for } \\
\text { antisocial }\end{array}$ \\
\hline & & & $\begin{array}{l}\text { Social status } \\
\text { of the target } \\
\text { (victim) }\end{array}$ & 27 & 4.5 & & $18 n s$ & No preference \\
\hline \multirow[t]{4}{*}{$\begin{array}{l}\text { (6) Burns \& } \\
\text { Sommerville } \\
\text { (USA, 2014) }\end{array}$} & \multirow[t]{4}{*}{$\begin{array}{l}\text { Allocating } \\
\text { foods - } \\
\text { Movies (2D) }\end{array}$} & \multirow[t]{4}{*}{$\begin{array}{l}\text { Manual } \\
\text { choice - } \\
\text { Reaching } \\
\text { behavior }\end{array}$} & $\begin{array}{l}\text { Race of the } \\
\text { fair } \\
\text { distributor } \\
\text { (same-race) }\end{array}$ & 15 & 40 & \multirow[t]{4}{*}{$\begin{array}{l}\text { Fair choice } \\
\text { score }(0-1)\end{array}$} & $0.45 n s$ & No preference \\
\hline & & & $\begin{array}{l}\text { Race of the } \\
\text { fair } \\
\text { distributor } \\
\text { (other-race) }\end{array}$ & 15 & 40 & & $0.55 n s$ & No preference \\
\hline & & & $\begin{array}{l}\text { Race of } \\
\text { recipient } \\
\text { advantaged } \\
\text { (same-race) }\end{array}$ & 15 & 40 & & $0.42 n s$ & No preference \\
\hline & & & $\begin{array}{l}\text { Race of } \\
\text { recipient } \\
\text { advantaged } \\
\text { (other-race) }\end{array}$ & 15 & 40 & & $0.59 \mathrm{~ns}$ & No preference \\
\hline \multirow[t]{4}{*}{$\begin{array}{l}\text { (7) Scola et al. } \\
\text { (France, 2015) }\end{array}$} & \multirow{4}{*}{$\begin{array}{l}\text { Playing a ball } \\
\text { game - } \\
\text { Cartoons (2D) }\end{array}$} & \multirow{4}{*}{$\begin{array}{l}\text { Manual } \\
\text { choice - } \\
\text { Reaching } \\
\text { behavior }\end{array}$} & $\begin{array}{l}\text { Appearance } \\
\text { of the }\end{array}$ & $12-24$ & 14 & \multirow{4}{*}{$\begin{array}{l}\text { No. infants } \\
\text { choosing the } \\
\text { prosocial agent }\end{array}$} & $9 n s$ & No preference \\
\hline & & & $\begin{array}{l}\text { prosocial } \\
\text { agent } \\
\text { (Cond1.) } \\
\end{array}$ & $24-36$ & 25 & & $17^{*}$ & $\begin{array}{l}\text { Preference for } \\
\text { prosocial }\end{array}$ \\
\hline & & & Appearance & $12-24$ & 14 & & $9 n s$ & No preference \\
\hline & & & $\begin{array}{l}\text { prosocial } \\
\text { agent }\end{array}$ & $24-36$ & 25 & & $18 *$ & $\begin{array}{l}\text { Preference for } \\
\text { prosocial }\end{array}$ \\
\hline
\end{tabular}


(Cond2.)

Note. $n s=$ nonsignificant at $\alpha=.05 ; \mathrm{s}=$ seconds; Cond. = experimental condition.

$*$ one-tailed $p<.05$. ** one-tailed $p<.01$. *** one-tailed $p<.001$. 